\title{
Matters of Life and Death: An Experimental Study Investigating Psychological Interventions to Encourage the Readiness for End-of-Life Conversations
}

\author{
Pia von Blanckenburg ${ }^{a}$ Nico Leppin ${ }^{a}$ Katharina Nagelschmidt ${ }^{a}$ \\ Carola Seifart ${ }^{\mathrm{b}}$ Winfried Rief ${ }^{\mathrm{a}}$ \\ a Department of Clinical Psychology and Psychotherapy, Philipps University of Marburg, Marburg, Germany; \\ b Institutional Review Board, Clinical Ethics, Philipps University of Marburg, Marburg, Germany
}

\section{Keywords}

End-of-life communication - Death anxiety · Psychological intervention · Existential interventions

\begin{abstract}
Introduction: Talking about death and dying is evoking discomfort in many persons, resulting in avoidance of this topic. However, end-of-life discussions can alleviate distress and uncertainties in both old and young adults, but only a minority uses this option in palliative care. Even in healthy populations, talking about death is often seen as alleviative and worthwhile, but rarely initiated. Objective: To investigate different psychological interventions (a) encouraging the readiness for end-of-life discussions and (b) changing death attitudes in healthy adults of different ages. Methods: 168 participants were randomized to four different interventions (IG1: value-based intervention with end-of-life perspective, IG2: motivation-based intervention with end-of-life perspective, IG3: combination of IG1 and IG2, CG: control group). Primary outcome was the readiness to engage in end-of-life topics. Secondary outcomes were fear of death, fear of dying and death acceptance. Assessments took place before, di-
\end{abstract}

karger@karger.com www.karger.com/pps

Karger $\stackrel{\text { ' }}{5}$

BOPEN ACCESS
(C) 2020 The Author(s)

Published by S. Karger AG, Basel

This is an Open Access article licensed under the Creative Commons Attribution-NonCommercial-4.0 International License (CC BY-NC) (http://www.karger.com/Services/OpenAccessLicense), applicable to the online version of the article only. Usage and distribution for commercial purposes requires written permission. rectly after the intervention and at 2 weeks of follow up. $\boldsymbol{R e}$ sults: IG2 and IG3 reported significantly more changes in the readiness to engage in end-of-life discussions than the CG $\left(F[5.61,307]=4.83, p<0.001, \eta p^{2}=0.081\right)$ directly after the intervention. The effect of IG3 remained stable at the followup. There were no significant effects of the interventions on end-of-life fears or death acceptance. Acceptability of the interventions was very high. Conclusions: Short interventions can be useful to encourage end-of-life discussions and could be integrated in health care programs. The efficacy and effectiveness of these short interventions in palliative patients are currently examined.

(c) 2020 The Author(s)

Published by S. Karger AG, Basel

\section{Introduction}

In Germany, the annual death rate will increase in the future because of an aging population [1]. Even though the majority of deaths are accounted for by older people, young adults can also be affected for example due to an unfavorable course of a cancer disease [2]. It is generally accepted as an existential feature given that all human be- 
ings have to die one day, and there appear to be global and cross-cultural similarities on what is important at the end of life [3-5]. This includes the possibility to be with loved ones, to die with dignity, to be self-determined, to be free of pain, and not to be a burden. Moreover, most persons wish to die at home and not in hospitals $[6,7]$.

To enable patients' end-of-life preferences within personalized care and ensure high congruence between the wishes and reality, open conversations about death, dying and care are of high importance. End-of-life discussions are associated with less aggressive medical treatment close to death, and therefore with better quality of life [8, 9]. Moreover, end-of-life communication is related to lower health care costs and reduced caregiver burden [10, 11]. Caregivers' bereavement adjustment and quality of life were better when end-of-life discussions took place $[8,12]$. One possibility to realize a structured discussion about relevant end-of-life topics is including patients' values in advance care planning [13]. Advance care planning can alleviate uncertainties and is associated with higher satisfaction with palliative care in both old and young adults $[12,14,15]$.

Despite these advantages, end-of-life communication is challenging due to numerous barriers such as lacking knowledge $[16,17]$. Important psychological aspects in end-of-life communication are the attitudes and emotions regarding death as death anxiety. Research about death attitudes and death anxiety spans from the 50 s over the 70 s until now $[18,19]$. In times of COVID-19 these topics appear especially relevant [20]. The psychosomatic syndrome of death anxiety - thanatophobia (Diagnostic Criteria for Psychosomatic Research) includes the fear of death and avoidance of news that remind of death [21]. Moreover, death anxiety can be seen as a transdiagnostic construct and a possible core fear in mental disorders such as hypochondria, panic disorder and depressive disorders [22]. Thus, death anxiety was shown to be a strong predictor of various aspects of psychopathology [23]. In an oncological sample $8.2 \%$ of the patients showed the syndrome of thanatophobia [24], but it is also present in healthy populations $[18,25]$. Thanatophobia or death anxiety can be a relevant factor to avoid end-of-life topics, whereas death acceptance is associated with a higher degree of awareness and abilities to reflect on death and dying $[26,27]$. Thus, attitudes toward death are relevant determinants to address in this context.

The ambivalence seems to be strong: although many persons perceive end-of-life discussions and advance care plans as important, rates of uptake are relatively low in cancer patients and in the general population $[16,28]$.
Research showed that patients prefer to speak very late about end-of-life topics [29] which can sometimes be too late. There are different steps necessary to complete an advance care plan or an end-of-life discussion which can be identified with the transtheoretical model of behavior change [30]. Fried et al. [30] argue that individualized interventions targeted at individual stages of behavior change for different components of end-of-life discussions may be useful. If persons do not feel ready to talk about end-of-life issues, it can cause harm to engage them in such discussions [31]. Thus, it might be relevant to first address the readiness and clarify personal values before starting an end-of-life conversation. The ambivalence should be addressed by motivation-focused approaches [32].

Typical attitudes of the general population are characterized by a paradox: most people want to die in an environment that is informed about their preferences for the final period of life [16]. However, emotional, cognitive, communicative, relational and external processes can hinder end-of-life communication within the family [33]. A recent review showed that the most frequently reported barriers were emotional and cognitive processes such as protective buffering or belief in positive thinking [33]. Thus, relatives attempt to protect their loved ones from emotional upset and psychological burden (e.g., "I don't want to cause any sadness"), wish to maintain hope and optimism (e.g., discussing death makes it a reality) or believe that they already know the preferences of the other [34]. Moreover, they attempt to be able to continue their family roles and relationships (e.g., to maintain their hierarchical role and identity as the parent or the strong partner and not as weak) [35]. Considering that end-oflife discussions can be a valuable, intense and existential experience, the avoidance of these discussions is questionable even in healthy people. Despite the universality of dying, scientifically based knowledge and experience of how to lead these discussions in the general population are low.

There already exist some end-of-life communication interventions targeting patients, health care professionals or other stakeholders [36], but no study explicitly focuses on the individual readiness. Furthermore, a review showed that research is widely lacking in encouraging healthy persons in end-of-life discussions [37]. Only a few empirical studies exist that evaluate interventions targeting healthy populations, and no study had a controlled design. The review pointed out that it is essential to actively engage people rather than passively providing information and to ensure a proper setting for interven- 
tions. Nevertheless, data are limited, and there is a need for more research about beneficial and feasible interventions [37]. Moreover, interventions that address end-oflife attitudes and death anxiety in several populations (general population as well as patients with advanced cancer) were shown to be effective, but there exist a large heteronomy of study quality $[38,39]$ and the need for randomized controlled trials (RCTs). Thus, the research question of this experimental (randomized) study was whether different microinterventions (including an existential focus on values and motivation) can (a) increase the readiness to engage in end-of-life topics and (b) increase death acceptance and decrease end-of-life fears. Additionally, this study evaluates the effect of different age ranges on the mentioned variables.

\section{Materials and Methods}

\section{Study Design}

Accompanying a large RCT with palliative cancer patients (registered under ClinicalTrials.gov, NCT03387436), this trial used an experimental design and aimed to analyze two different microinterventions and the combination of those in a healthy sample. Results are compared to a control group receiving a neutral intervention. Ethical approval was obtained from the respective local ethics committees (ref. No. 2018-5k-2). In the aforementioned RCT with palliative cancer patients (Hand-in-Hand Study), the combination approach will be evaluated and compared to treatment as usual and a control intervention. Thus, the aim of this experimental study was to gain further insights into the two different component parts of the psychological intervention (dismantling design).

Data were collected between April 2018 and July 2018. To enable subanalyses about age differences, participants from two different stages in life, e.g. a younger (aged 18-35 years) and an older (aged 65-88 years) sample were included. Participants were recruited through study announcements in public places such as libraries, family doctor practices, adult education centers, retirement homes, university classes and rehabilitation sport. As an incentive, participants could take part in a prize draw for vouchers redeemable with a local voucher card. Persons had to be able to give informed consent and to have sufficient German language skills. Exclusion criteria were the presence of any life-threatening illness and severe mental illness (e.g., psychosis, suicidality). After providing written informed consent, all patients received a structured information about death statistics in Germany, in order to homogenize knowledge and salience of death. Then, participants filled in the baseline questionnaire (online via Uniparc or paperpencil) and were randomly assigned to receive the value-based intervention (IG1), the motivation-focused intervention (IG2), the combination of IG1 and IG2 (IG3) or the control intervention (CG). The allocation sequence was computer-generated in blocks of 20 persons by an independent researcher of the working group. The intervention took place personally 1 week after the baseline questionnaire (preintervention assessment) at the psychological institute of Marburg. Immediately after the intervention, the par- ticipants completed the second questionnaire (postintervention assessment). Two weeks after the intervention the participants got the follow-up questionnaire online via a link in an e-mail or by paper-pencil on the postal way with an addressed return envelope. Assessment took place under blind conditions. Moreover, participants were blinded after assignment to the intervention. After the follow-up assessment, they received clarifications about the study aims and their intervention group.

\section{Psychological Microinterventions}

Participants received one individual microintervention of 40 50 min (combination group 60-75 min) duration by a master student of clinical psychology. All master students received intensive training and supervision by experienced clinical psychologists. All sessions were audiotaped to control for therapeutic allegiance and to ensure high quality of the supervision process.

Value-Based Intervention with an End-of-Life Perspective

The value-based intervention was designed on the basis of dignity therapy $[40,41]$ which is a psychological intervention in palliative care. Participants were asked the questions of the Dignity Therapy Question Protocol, e.g. "Tell me a little about your life history; particularly the parts that you either remember most or think are the most important" or "Are there particular things that you feel still need to be said or things that you want to take the time to say once again?" An overview over the whole protocol is provided in the online supplementary Appendix B (for all online suppl. material, see www.karger. com/doi/10.1159000511199). The most important sentences were written or drawn on a record card that the participant could take along. The aim of the value-based intervention was to clarify the person's individual values in life as one of the first steps in end-of-life conversations or/and an advance care planning process [42].

\section{Motivation-Focused Intervention with an End-of-Life}

Perspective

This motivation-focused intervention was designed on the basis of motivational interviewing [32] which is a psychological style to enhance readiness for change by taking into account people's ambivalence. Participants were asked about the barriers and the advantages of engaging in end-of-life topics and starting end-oflife discussions, e.g. "What difficulties could come along for you if you speak about the end of life, death and dying with your loved ones?", "Which benefits could such talks have?" or "What would be important topics to speak about in regard of your own end of life?" The most important sentences were written on a record card that the participant could take along. The aim of the motivationfocused intervention was to improve people's readiness to engage in end-of-life topics as the possible first step in end-of-life conversations or/and an advance care planning process.

\section{Combined Intervention}

The combined intervention was a combination of the valuebased and the motivation-focused intervention.

\section{Control Intervention}

The control intervention was designed as a discussion about general health topics like healthy nutrition, workout, alcohol consumption and donating blood. Participants were asked about their own rules for a healthy life, e.g. "How many minutes do you work out in the week?" or "How important is it for the society that persons do- 
nate blood?" The aim of the control group was to discuss healthrelated topics in life in the same amount of time as in the intervention groups, but not with a direct focus on end-of-life topics.

\section{Assessment}

Readiness to Engage in End-of-Life Topics

Readiness to engage in end-of-life topics was measured with 13 items (e.g. "Thinking about the end of life is part of life" or "For me it makes sense to talk about death and the dying process with my family/friends"). For the validation and psychometric evaluation of the Readiness for End-of-Life Conversations scale, see Berlin et al. [43]. The items were rated on a 6-point Likert scale from 0 "do not agree at all" to 5 "fully agree" (online suppl. Appendix A). A higher sum score indicates a higher readiness to engage in end-of-life topics. Internal consistency of the scale was high (Cronbach's $\alpha=0.86$ ).

Moreover, patients were asked if they have an advance directive ("yes" or "no") and in which individual stage of change after the transtheoretical model (precontemplation, contemplation, preparation, action, maintenance) they are in regard of fulfilling an advance directive according to Fried et al. [30].

\section{End-of-Life Fears and Death Acceptance}

The Multidimensional Orientation toward Dying and Death Inventory assesses attitudes about death in 8 subscales [44]. Due to economical reasons, in this study only the 3 subscales Fear of one's own death with 6 items ("Thinking beyond the threshold of my death makes me afraid"), Fear of one's own dying process with 8 items (e.g. "I am afraid of dying a painful death one day") and Acceptance of dying and death with 8 items (e.g. "Basically, I am ready to accept that I have to die one day") were applied. The items are scored in a 4-point Likert scale ranging from 0 to $3(0=$ agree not at all; 3 = agree almost totally). Higher sum scores indicate more fear or a larger acceptance, depending on the scale. Cronbach's $\alpha$ for the subscales ranged from 0.82 to 0.92 .

Depressive Symptoms and Sociodemographic Variables

Depressive symptoms were measured with the Patient Health Questionnaire PHQ-9 [45]. The questionnaire assesses depressive symptoms with 9 items. The items are scored in a 4-point Likert scale ranging from 0 to $3(0=$ not at all; $3=$ nearly every day). Higher sum scores indicate more depressive symptoms (Cronbach's $\alpha=0.89$ ).

Age, education, gender, nationality, marital status, religiosity ("yes" or "no") and chronic disease ("yes" or "no") were assessed within the baseline questionnaire. Moreover, participants were asked "if they have ever been faced with death, e.g. through illness or an accident" ("yes" or "no"), and "if they have experienced the death of a close person" ("yes" or "no").

\section{Participants' Evaluation of the Intervention}

Participants evaluated the intervention on three statements rated on a 6-point Likert scale from 1 "do not agree at all" to 6 "fully agree" as part of the postintervention questionnaire ("the intervention was helpful," "I felt comfortable during the intervention" and "The content of the intervention was displeasing to me").

\section{Data Analysis}

According to the results of a power analysis calculated with $\mathrm{g}^{*}$ power, a minimum of 116 participants was required in order to achieve a small effect in a mixed-design analysis of variance (ANOVA) with $80 \%$ power and a significance level of 0.05 . We expected a small effect on the basis of prior research [39]. First, a data screening was conducted, testing the assumptions of multivariate analyses of variance (MANOVA) and mixed ANOVAs. In cases of a violation of the sphericity, the Greenhouse-Geiser correction was used. For a dropout analysis, a MANOVA was conducted to analyze possible baseline differences between dropouts and study completers. Next, another MANOVA was performed to examine possible baseline differences between the four different intervention groups. Subsequently, a mixed $4 \times 3$ ANOVA with the withinsubject factor "time" and the between-subject factor "group" for the dependent variable readiness was conducted. Bonferroni-corrected post hoc tests were performed to control for problems of multiple testing ( $\alpha$-error accumulation). Analyses of covariance were performed to control for age, gender, education, chronic illness, death of a close person and prior contact with death. Further MANOVAs were conducted to analyze changes in end-of-life fears and death acceptance and investigate effects of different age groups. All statistical analyses were performed using SPSS Statistics 24 for Windows.

\section{Results}

\section{Participant Flow}

Out of 269 participants who started to fill in the baseline assessment, 221 finished the assessment. 28 participants declined participation, and 9 baseline questionnaires were not coded correctly and could not be assigned. Thus, 184 persons were randomized to IG1 $(n=47)$, IG2 $(n=42)$, IG3 $(n=48)$ and CG $(n=47)$. Of those, 168 completed all assessments with a valid code (91.3\%) (Fig. 1). Dropout analyses were conducted between the persons who further participated in the study $(n=168)$ and those who did not $(n=28)$. In a MANOVA the dropouts had higher reported values in the variables "fear of death" $\left(F[1,191]=21.90, p<0.001, \eta_{p}{ }^{2}=0.10\right)$, "fear of dying" $\left(F[1,191]=10.45, p=0.001, \eta_{p}{ }^{2}=0.05\right)$ and lower values in "death acceptance" $\left(F[1,191]=11.00, p=0.001, \eta_{p}{ }^{2}=\right.$ $0.05)$. No significant differences appeared in the variable "readiness to engage in end-of-life topics" $(F[1,191]=$ 2.41, $\left.p=0.122, \eta_{p}{ }^{2}=0.01\right)$.

\section{Baseline Characteristics}

All baseline sociodemographic characteristics are shown in Table 1. There were no significant differences between the groups.

\section{Participants' Evaluation of the Microintervention}

All interventions were equally evaluated as very positive. There were no significant differences between the groups. $94.4 \%$ of all participants found the interventions 


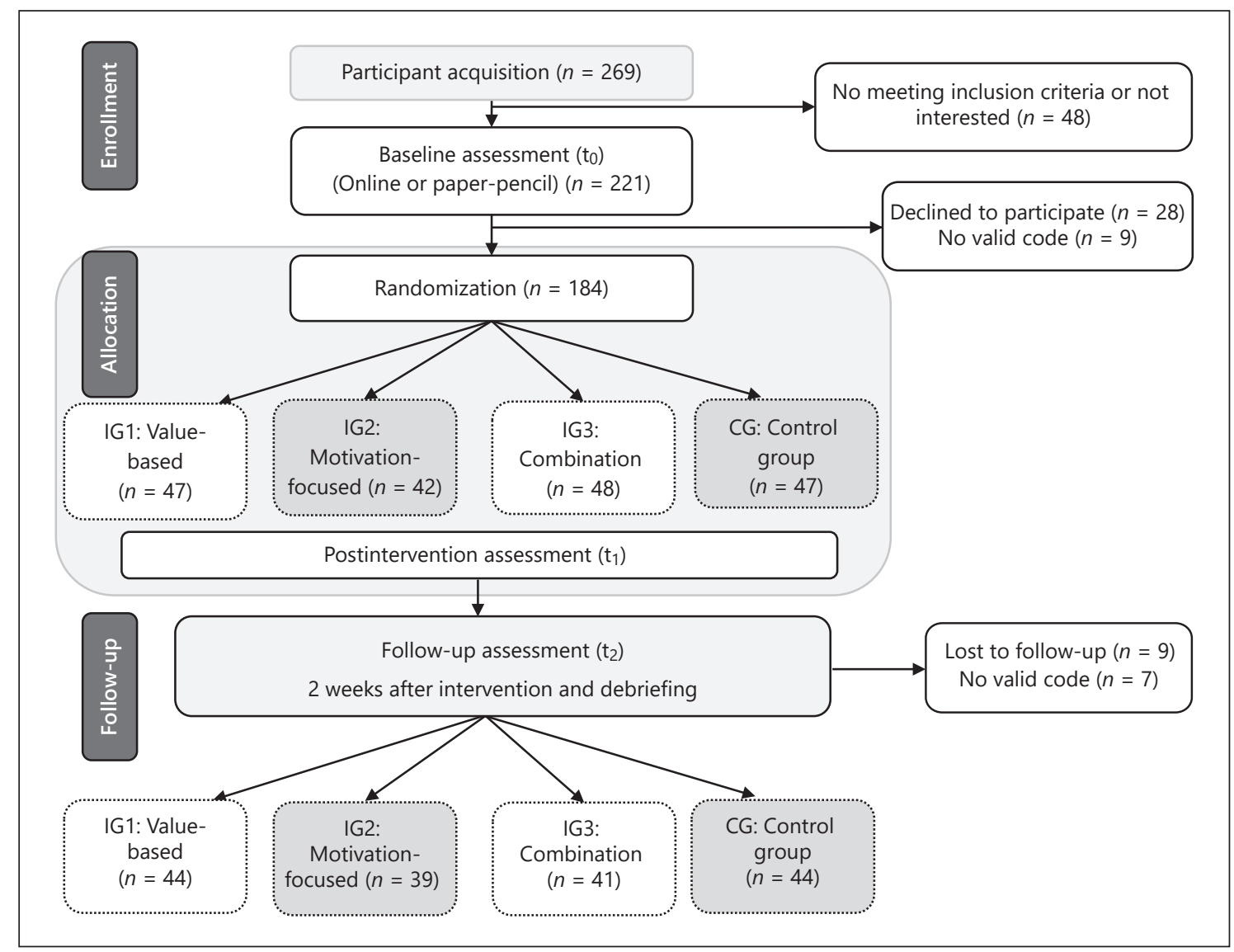

Fig. 1. Trial profile.

rather helpful to very helpful in the IGs and $90.9 \%$ in the CG. Most participants felt rather comfortable to very comfortable with the interventions $(98.4 \%)$ in the IGs and in the CG (97.7\%). Nobody from the CG, 3 persons from IG1, 4 persons from IG2 and 1 person from IG3 evaluated the contents of the interventions as rather challenging to very challenging. The challenging rating was negative correlated with baseline readiness ( $r=-0.147, p=$ 0.028 ) and positive correlated with baseline fear of death $(r=0.185, p=0.020)$ indicating that persons who had lower scores in the readiness and higher scores in fear of death rated the interventions as more burdening. Moreover, there was a significant correlation if a person had faced death $(r=-0.220, p=0.007)$. There were no significant correlations between the challenging rating and fear of dying $(r=0.018, p=0.016)$, death acceptance $(r=$ $-0.111, p=0.076)$, depression $(r=0.041, p=0.326)$, age $(r=-0.066, p=0.234)$, gender $(r=0.013, p=0.444)$ or religiosity $(r=-0.060, p=0.254)$.

Psychological Interventions Encouraging End-of-Life Conversations
Changes in Readiness to Engage in End-of-Life Topics

A mixed $4 \times 3$ ANOVA (with Greenhouse-Geisser correction) with the within-subject factor "time" and the between-subject factor "group" revealed for the dependent variable readiness a significant effect of "time" $\left(F[1.87,306.9]=72.90, p<0.001, \eta_{p}^{2}=0.31\right)$ and a significant "time $\times$ group interaction" $(F[5.61,306.9]=4.83$, $\left.p<0.001, \eta_{p}{ }^{2}=0.081\right)$, whereas no main "group" effect was found $\left(F[3,164]=1.49, p=0.220, \eta_{p}^{2}=0.026\right)$. The significant interaction effect indicated different effects on readiness between the study groups. Mean values and SD for the analyses are summarized in Table 2. The results remained stable after controlling for possible confounders such as age, gender, education, chronic illness, death of a close person and being faced with death. Analyzing the differences in estimated mean scores of the readiness before and after the intervention, Bonferroni-corrected post hoc tests revealed that IG2 (mean difference, $M_{\text {diff }}=$ -4.03 , standard error, $\mathrm{SE}=1.38, p=0.025, d=0.60)$ and 
Table 1. Demographic characteristics at baseline of the individuals

\begin{tabular}{|c|c|c|c|c|}
\hline & IG1 $(n=44)$ & IG2 $(n=39)$ & IG3 $(n=41)$ & $\mathrm{CG}(n=44)$ \\
\hline \multicolumn{5}{|l|}{ Mean age (SD), years } \\
\hline Younger group & $23.57(3.12)$ & $23.00(3.90)$ & $22.24(2.74)$ & $22.57(3.16)$ \\
\hline Older group & $72.09(5.54)$ & $70.38(5.44)$ & $71.20(7.14)$ & $72.74(6.80)$ \\
\hline \multicolumn{5}{|l|}{ Gender } \\
\hline Female & $32(72.7 \%)$ & $26(66.6 \%)$ & $29(70.7 \%)$ & $32(72.7 \%)$ \\
\hline Male & $12(27.3 \%)$ & $13(33.3 \%)$ & $12(29.3 \%)$ & $12(27.3 \%)$ \\
\hline Nationality & 97.7\% German & $94.9 \%$ German & $100 \%$ German & 97\% German \\
\hline \multicolumn{5}{|l|}{ Education, $n$} \\
\hline$<10$ years & $14(31.8 \%)$ & $9(23.1 \%)$ & $5(12.2 \%)$ & $12(27.3 \%)$ \\
\hline 11 years and more & $30(68.2 \%)$ & $30(76.9 \%)$ & $36(87.8 \%)$ & $32(72.7 \%)$ \\
\hline \multicolumn{5}{|l|}{ Marital status, $n$} \\
\hline Single & $16(36.4 \%)$ & $13(33.3 \%)$ & $15(36.6 \%)$ & $16(36.4 \%)$ \\
\hline Married/partner & $23(52.2 \%)$ & $18(35.9 \%)$ & $18(44 \%)$ & $17(38.8 \%)$ \\
\hline Widowed & $4(9.1 \%)$ & $5(12.8 \%)$ & $5(12.2 \%)$ & $8(18.2 \%)$ \\
\hline Divorced & $1(2.3 \%)$ & $3(7.7 \%)$ & $3(7.3 \%)$ & $2(4.5 \%)$ \\
\hline \multicolumn{5}{|l|}{ Other, $n$} \\
\hline Chronic disease & $11(25 \%)$ & $12(30 \%)$ & $8(19.5 \%)$ & $13(29.5 \%)$ \\
\hline Religiosity & $29(65.9 \%)$ & $22(56.4 \%)$ & $18(43.9 \%)$ & $29(66.0 \%)$ \\
\hline Depression PHQ & $12.5(3.08)$ & $12.07(2.33)$ & $12.65(2.52)$ & $13.27(3.84)$ \\
\hline Advance directive & $15(34.1 \%)$ & $14(35.9 \%)$ & $12(29.3 \%)$ & $16(36.4 \%)$ \\
\hline Death of a close person & $22(50 \%)$ & $14(35.9 \%)$ & $22(53.7 \%)$ & $27(61.4 \%)$ \\
\hline Faced with death & $22(50 \%)$ & $22(56.4 \%)$ & $30(73.2 \%)$ & $30(68.2 \%)$ \\
\hline
\end{tabular}

PHQ, Patient Health Questionnaire.

Table 2. Outcome measures at baseline, directly after the intervention and 2 weeks following the intervention in participants in the value-based group (IG1), the motivation-focused group (IG2), the combination group (IG3) and the control group $(\mathrm{CG})$

\begin{tabular}{lcccc}
\hline & IG1 $(n=44)$ & IG2 $(n=39)$ & IG3 $(n=41)$ & CG $(n=44)$ \\
\hline Readiness (0-65) & & & \\
Baseline & $38.66(8.30)$ & $40.72(9.29)$ & $38.37(11.39)$ & $39.88(10.10)$ \\
After intervention & $43.43(6.95)$ & $46.39(8.22)$ & $46.04(7.81)$ & $41.52(7.15)$ \\
2 weeks of follow-up & $42.0(8.43)$ & $45.77(8.75)$ & $45.44(8.30)$ & $42.11(7.70)$ \\
\hline Fear of death (0-18) & & & \\
Baseline & $4.48(3.99)$ & $3.38(4.13)$ & $4.90(4.68)$ & $4.80(4.34)$ \\
After intervention & $4.36(3.61)$ & $3.28(3.66)$ & $4.15(3.85)$ & $4.98(4.21)$ \\
2 weeks of follow-up & $4.59(4.70)$ & $3.21(3.99)$ & $4.71(4.63)$ & $4.64(4.18)$ \\
\hline Fear of dying (0-24) & & & & $12.36(5.35)$ \\
Baseline & $13.00(5.90)$ & $13.26(5.39)$ & $14.20(5.52)$ & $12.05(5.49)$ \\
After intervention & $13.14(5.60)$ & $14.28(5.72)$ & $14.61(5.46)$ & $13.05(6.07)$ \\
2 weeks of follow-up & $12.52(6.45)$ & $12.77(6.67)$ & $14.54(6.23)$ & $12.57(6.07)$ \\
\hline Death acceptance (0-24) & & & & $18.23(4.88)$ \\
Baseline & $17.16(5.33)$ & $17.21(6.50)$ & $18.05(6.30)$ & $18.84(4.45)$ \\
After intervention & $18.18(4.75)$ & $18.53(6.91)$ & $18.76(5.75)$ & $18.38(6.14)$ \\
2 weeks of follow-up & $17.45(5.19)$ & $18.80(6.42)$ & $18.00(6.10)$ & \\
\hline
\end{tabular}


Fig. 2. Differences in the estimated mean scores before versus after the intervention (a) and before versus 2 weeks following the intervention (b) in the value-based group (IG1), in the motivation-focused group (IG2), in the combination group (IG3) and in the control group (CG); error bars: \pm 1 standard error. EOL, end of life.

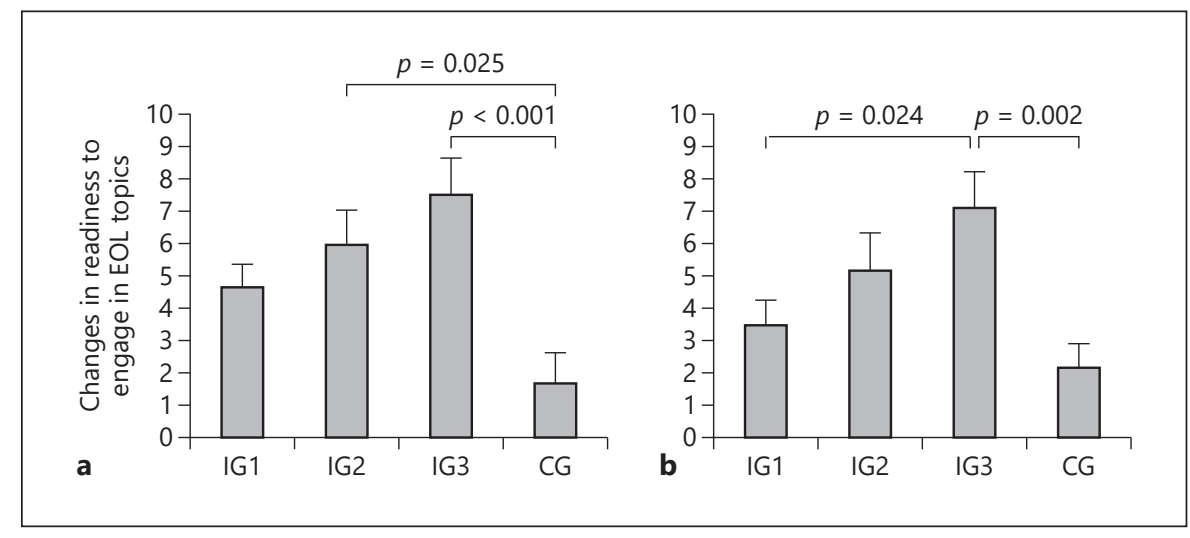

IG3 $\left(\mathrm{M}_{\text {diff }}=-6.05, \mathrm{SE}=1.37, p<0.001, d=0.88\right)$ but not IG1 $\left(\mathrm{M}_{\text {diff }}=-3.14, \mathrm{SE}=1.35, p=0.126\right)$ had greater changes in the readiness than the CG. These results indicated that the motivation-focused group and the combination group had more changes in their readiness to engage in end-of-life conversations after the intervention than the CG. Moreover, Bonferroni-corrected post hoc tests showed that IG3 $\left(\mathrm{M}_{\text {diff }}=-4.85, \mathrm{SE}=1.31, p=0.002\right.$, $d=0.78)$ but not IG1 $\left(\mathrm{M}_{\text {diff }}=-1.09, \mathrm{SE}=1.28, p=1.0\right)$ and IG2 $\left(\mathrm{M}_{\text {diff }}=-2.82, \mathrm{SE}=1.33, p=0.211\right)$ had greater changes in the readiness from baseline to the follow-up than the CG. IG1 showed smaller changes than IG3 from baseline to follow-up $\left(\mathrm{M}_{\text {diff }}=-3.90, \mathrm{SE}=1.33, p=0.024\right.$, $d=0.64$ ) (Fig. 2). These results indicated that the readiness significantly increased in the combination group from baseline to 2 weeks after the intervention compared to the CG and the value-based group. Additionally, the respective readiness score over all groups was associated with the transtheoretical model behavior stage after the intervention $\left(\eta^{2}=0.266\right)$ and at follow-up $\left(\eta^{2}=0.337\right)$ indicating that persons with higher readiness scores were more willing to complete a living will or already did so.

\section{Changes in End-of-Life Attitudes}

In a mixed $4 \times 3$ MANOVA with the within-subject factor "time" and the between-subject factor "group" with fear of death, fear of dying and death acceptance as dependent variables, a significant effect of time $(V=0.90$, $\left.F[6,159]=2.65, p<0.019, \eta_{p}{ }^{2}=0.09\right)$ was found. Subsequent contrasts showed a higher score of death acceptance from baseline to postintervention $(F[1,164]=6.24$, $\left.p=0.014, \eta_{p}^{2}=0.037\right)$ with a return to baseline level at follow-up $\left(F[1,164]=1.84, p<0.226, \eta_{p}^{2}=0.009\right)$. Moreover, contrasts showed a significantly higher score of fear of dying from baseline to postintervention with a return to baseline level at 2 weeks of follow-up $(F[1,164]=0.95$, $\left.p<0.758, \eta_{p}{ }^{2}=0.001\right)$. There was no "time" effect on the reported fear of death $\left(F[1,160]=0.66, p=0.416, \eta_{p}{ }^{2}=\right.$ $0.004)$. Thus, persons of all groups reported higher death acceptance and higher fear of dying after the intervention but both values turned to baseline levels after 2 weeks. There was neither a main group effect $(V=0.94, F[9,394]$ $\left.=1.210, p=0.287, \eta_{p}^{2}=0.02\right)$ nor a significant "time $\times$ group interaction" effect $(V=0.94, F[18,450]=0.61, p=$ $\left.0.897, \eta_{p}{ }^{2}=0.02\right)$. The results stayed stable after controlling for possible confounders such as age, gender, education, chronic illness, death of a close person and being faced with death.

\section{Effects of Different Age Groups}

To investigate the moderating influence of age we included the two different age groups (young adults vs. older adults) in a mixed $2 \times 4 \times 3$ MANOVA with the between-subject factors "age group" and "intervention group" and the within-factor "time" for the dependent variables "readiness," "death acceptance," "fear of death" and "fear of dying" at the baseline measurement. There was no significant interaction of "age group" $\times$ "intervention group" $\times$ "time" $\left(F[24,465]=0.83, p=0.702, \eta_{p}{ }^{2}=\right.$ 0.041 ), indicating that age had no moderating role on the effect of the interventions. There was, however, a significant main effect of age group $(F[4,157]=10.81, p<0.001$, $\left.\eta_{p}{ }^{2}=0.216\right)$. Subsequent univariate analyses showed a significant direct effect of age on the reported readiness $(F[1$, $\left.160]=15.04, p<0.001, \eta_{p}^{2}=0.086\right)$, death acceptance $\left(F[1,160]=21.39, p<0.001, \eta_{p}^{2}=0.118\right)$, fear of death $\left(F[1,160]=22.87, p<0.001, \eta_{p}^{2}=0.125\right)$ but not on the reported fear of dying $\left(F[1,160]=0.66, p=0.416, \eta_{p}^{2}=\right.$ 0.004 ). Thus, persons in an older age range showed a higher readiness to talk about the end of life, reported a 
higher death acceptance and less fear of their own death, while older persons and young persons showed the same amount of fear of their own dying process.

\section{Discussion}

The central aim of this experimental design study was to examine the effect of three microinterventions (valuebased, motivation-focused, the combination of both) on the readiness for end-of-life discussions and end-of-life attitudes in healthy adults of different ages. The motivation-focused group and the combination group demonstrated higher readiness in end-of-life conversations after the intervention than the CG. This result was stable at the follow-up for the combination group. In contrast, no group effects on death attitudes such as fear of death, fear of dying and death acceptance were found.

The main finding, i.e. that the combination group had the highest effect on the readiness, is in line with prior studies, showing that involving values can facilitate the initiation of an end-of-life talk [42]. Including values and dignity-related questions might cause less distress and act as an icebreaker [46]. Nevertheless, to speak about values and dignity alone does not seem to be sufficient to attain a higher engagement in end-of-life themes. A motivation-focused approach that considers persons' ambivalence seems to be helpful. A relevant approach can be the concept of "double awareness" which has been developed within the psychotherapy for patients living with advanced cancer and takes into account the impossibility of avoiding awareness of death while continuing to engage in life [47]. Encouraging double awareness means to promote the flexibility of mind between life awareness and death awareness and seems to be a very useful approach in this context. Another relevant part of the motivation-focused approach includes the provision of information, considering that lack of knowledge represents a relevant barrier in engaging in end-of-life discussions $[48,49]$. While prior studies have used different strategies for older persons (e.g., peer education program on end-of-life planning) and younger persons (e.g., an arts project that brought together hospice users and school pupils) [37], in this study the same interventions seem to work for both, older and younger adults. Thus, the interventions seem to be flexible enough to consider the participants at their stages of readiness in the transtheoretical model of behavior change. Further research should evaluate these microinterventions in other settings, for example with patients with cancer in palliative settings.
It would also be of interest whether the interventions could be adapted to an online version to enable easier utilization.

The finding that the interventions were widely evaluated as helpful underlines the feasibility of the interventions. It seems to be useful to start discussing one's own end of life early in life, even when it is not acute $[50,51]$. On one hand, persons engage more in end-of-life topics, when it is more relevant for them. On the other hand, the time proximate to acute dying is often experienced as highly demanding and tense for dying persons and their families. Of note, also young people considered the discussions as valuable and helpful, e.g. to live their own lives more consciously and meaningfully [52]. Conversations earlier in life may facilitate preparations for substitute decision-making on a critically ill person's behalf. Previous research pointed out a gap between perceived and actual preparedness to be a substitute decision-maker for a loved one with a critical illness. In one study, $73 \%$ of 404 Canadian persons felt prepared to be a substitute decisionmaker, although $45.1 \%$ reported never having had meaningful conversations with loved ones to understand their wishes in the event of critical illness [53]. Thus, announcing advance care planning earlier in adulthood (e.g., beginning with healthy adults) might be helpful to warrant that the process of advance care planning includes continuing contemplation and conversations of goals of care. Preferably, advance care planning is nothing that is ever completed, but a process that should be addressed and readdressed across the adult lifespan [54]. It could be helpful to speak about these topics early in life to build on these discussions in critical times when persons become seriously ill.

Nevertheless, 8 persons (both young and older adults) evaluated the contents of the interventions as rather challenging to very challenging. This finding shows that even in persons who are not affected by the threat of a prompt death (like palliative cancer patients), end-of-life-related topics are difficult to speak about. Because death anxiety was associated with higher burden through the intervention and with higher dropout rates after the baseline measurement, the syndrome of thanatophobia including the wish to avoid death-related topics has to be taken into account [21]. Other psychological constructs that appear to be relevant are neuroticism, less sense of coherence or less mindfulness [55]. Interestingly, also persons who faced death in other contexts rated the intervention as more challenging. All these points have to be considered when addressing these topics to more affected persons. 
Persons of an older age showed a higher readiness to talk about the end of life, reported a higher death acceptance and less fear of their own death than young persons, which is in line with prior research [56]. Although death and dying become more salient with higher age, the fear of death often decreases. Interestingly, the fear of dying was the same in the older and the younger sample. The results are partly consistent with a representative German study that found a higher approval of older persons in the item "People are more afraid of the process of dying than they are of death" than in the younger sample [57]. A possible explanation for our results could be that fear of dying has more practical and specific components, for example the fear to suffer from pain or to die alone, which can be more salient in old but also in young adults. Network analyses about different death-related fears showed that fears were organized into two areas: one of more practical fears concerning the process of dying, and another of more psychosocial or existential concerns, for example missed opportunities [58]. Thus, a majority of older persons might find their ways to handle existential threat for example through religiosity but need support with their fears of the dying process while younger people feel more of an existential threat.

Our study could not find a group effect on fear of death, fear of dying and death acceptance. This finding is contrary to prior research, showing small to medium effects, especially of cognitive behavioral interventions [39]. A possible explanation is that our microintervention consisted only of one session of about $50 \mathrm{~min}$. Moreover, master students of clinical psychology and no advanced therapists conducted the interventions. It might need more time and more training to change such profound fears [22]. A longer intervention over a longer time period might be necessary to positively influence death anxiety (thanatophobia). Thus, a recent meta-analysis of interventions of death anxiety found a higher number of sessions associated with a greater reduction of death anxiety (the mean number of sessions that produced significant changes was 7.92) [39]. Interestingly, scores of death acceptance and fear of dying had both a small increase from baseline to postintervention in all groups and returned to baseline level after 2 weeks. This effect might emerge due to the repeated assessments including questions about death and dying. The finding that both - death acceptance and fear of dying - increased fits well in the concept of double awareness [47]. On one hand, persons might become

Psychological Interventions Encouraging

End-of-Life Conversations aware that life is limited, but on the other hand accept this fact as something valuable.

As clinical implication, the integration of short interventions encouraging end-of-life conversations can be valuable and helpful in general health care even in healthy persons but maybe also in clinical populations. Speaking about end-of-life topics might be alleviating and valueincreasing, the concept of double awareness seems to be helpful. Nevertheless, end-of-life encouraging interventions have to be held with sensitiveness, especially in persons with higher death anxiety and persons who have faced death in their lives.

\section{Strengths and Limitations}

One of the strengths of the study, among others, is that although research about death anxiety and death communication has been around for decades, robustly designed RCT studies in this area are rare. To our knowledge, there exist more observational studies and fewer experimental studies comparing different end-of-life encouraging interventions. Moreover, our study included a relatively broad sample allowing comparisons between younger and older adults.

Following the methodological recommendations for trials of psychological interventions [59], some methodical limitations have to be considered in this study. The maladaptive illness behavior of thanatophobia was not checked as described by the diagnostic criteria for psychosomatic research $[21,60]$. Medication intake was not assessed, and no observer-rated tools were used; the study only focused on patient-reported outcomes. Thus, it would have been interesting to assess on a behavioral level, whether persons will have conducted end-of-life discussions and advance care planning in the months following the intervention. Moreover, the primary outcome was revealed from a self-constructed questionnaire, which is validated by our research group. The survey might also have acted as an intervention itself, prompting more thoughts on preparation for the end of life in the CG. The finding that death acceptance and fear of dying increased over all groups (even in the CG) and decreased after 2 weeks might be explained by this point. Another important limitation was that the study sample was selective, as dropout analyses indicated that persons with higher fear of death and dying and less death acceptance were more at risk not to proceed in the study. Obviously, it would be interesting to especially include persons that avoid speaking about these topics and might benefit from such interventions to a higher extent. Nonetheless, the denial of death topics is a strategy, which can be appropri- 
ate in some phases of life and therefore must be accepted by investigators. Additionally, the follow-up in this study was only 2 weeks. In interventions that have long-term aims as the readiness to engage in end-of-life topics, longer follow-up terms would be preferable in forthcoming studies.

\section{Conclusion}

Short interventions can be useful to encourage the readiness to engage in end-of-life discussions also in healthy persons and could facilitate end-of-life discussions and advance care planning. The combination of value-based and motivation-focused aspects seem to be helpful. After participation, the evaluation of acceptability of these conversations was very high. Further research is needed to investigate these interventions with palliative samples (e.g., advanced cancer patients).

\section{Acknowledgments}

We thank Luisa Welsch, Charlotte Barth, Johannes Hauck, Sinja Kemper, Ingmar Connell, Franziska Schreiber and Nadja Angersbach for data collection.

\section{Statement of Ethics}

The study was conducted ethically in accordance with the Declaration of Helsinki. All participants have given their written informed consent, and the study protocol was approved by the respective local ethics committees (ref. No. 2018-5k-2).

\section{Conflict of Interest Statement}

The authors have no conflicts of interest to declare.

\section{Funding Sources}

The study was accompanying research to an ongoing large RCT funded by the German Federal Ministry of research and education to PD Dr. Carola Seifart. Funding-ID: 01GY1708. This funding source had no role in the design of this study and will not have any role during its execution, analyses, interpretation of the data or decision to submit results.

\section{Author Contributions}

P.B., N.L., K.N. and W.R. contributed to the design of the study. P.B., N.L. and K.N. administered the project. P.B. and K.N. performed the statistical analyses. P.B. drafted the manuscript. C.S. was responsible for the funding acquisition. All authors contributed to the interpretation of the data and offered critical revisions of the draft. All authors read and approved the final paper.

\section{References}

1 Scholten N, Günther AL, Pfaff H, Karbach U. The size of the population potentially in need of palliative care in Germany-an estimation based on death registration data. BMC Palliat Care. 2016 Mar;15(1):29.

2 Gondos A, Hiripi E, Holleczek B, Luttmann S, Eberle A, Brenner H; GEKID Cancer Survival Working Group. Survival among adolescents and young adults with cancer in Germany and the United States: an international comparison. Int J Cancer. 2013 Nov;133(9):2207-15.

3 Cox K, Bird L, Arthur A, Kennedy S, Pollock K, Kumar A, et al. Public attitudes to death and dying in the UK: a review of published literature. BMJ Support Palliat Care. 2013 Mar;3(1):37-45.

4 Steinhauser KE, Christakis NA, Clipp EC, McNeilly M, Grambow S, Parker J, et al. Preparing for the end of life: preferences of patients, families, physicians, and other care providers. J Pain Symptom Manage. 2001 Sep; 22(3):727-37.
5 Rietjens JA, van der Heide A, OnwuteakaPhilipsen BD, van der Maas PJ, van der Wal G. Preferences of the Dutch general public for a good death and associations with attitudes towards end-of-life decision-making. Palliat Med. 2006 Oct;20(7):685-92.

6 Gomes B, Higginson IJ, Calanzani N, Cohen J, Deliens L, Daveson BA, et al.; PRISMA. Preferences for place of death if faced with advanced cancer: a population survey in England, Flanders, Germany, Italy, the Netherlands, Portugal and Spain. Ann Oncol. 2012 Aug;23(8):2006-15.

7 Waller A, Sanson-Fisher R, Zdenkowski N, Douglas C, Hall A, Walsh J. The Right Place at the Right Time: Medical Oncology Outpatients' Perceptions of Location of End-of-Life Care. J Natl Compr Canc Netw. 2018 Jan; 16(1):35-41.

8 Wright AA, Zhang B, Ray A, Mack JW, Trice E, Balboni T, et al. Associations between endof-life discussions, patient mental health, medical care near death, and caregiver bereavement adjustment. JAMA. 2008 Oct; 300(14):1665-73.
9 Starr LT, Ulrich CM, Corey KL, Meghani SH. Associations Among End-of-Life Discussions, Health-Care Utilization, and Costs in Persons With Advanced Cancer: A Systematic Review. Am J Hosp Palliat Care. 2019 Oct; 36(10):913-26.

10 Fried TR, Bradley EH, O'Leary JR, Byers AL Unmet desire for caregiver-patient communication and increased caregiver burden. J Am Geriatr Soc. 2005 Jan;53(1):59-65.

11 Zhang B, Wright AA, Huskamp HA, Nilsson ME, Maciejewski ML, Earle CC, et al. Health care costs in the last week of life: associations with end-of-life conversations. Arch Intern Med. 2009 Mar;169(5):480-8.

12 Detering KM, Hancock AD, Reade MC, Silvester $\mathrm{W}$. The impact of advance care planning on end of life care in elderly patients: randomised controlled trial. BMJ. 2010 Mar; 340(1):c1345. 
13 Rietjens JA, Sudore RL, Connolly M, van Delden JJ, Drickamer MA, Droger M, et al.; European Association for Palliative Care. Definition and recommendations for advance care planning: an international consensus supported by the European Association for Palliative Care. Lancet Oncol. 2017 Sep; 18(9):e543-51.

14 Wiener L, Zadeh S, Battles H, Baird K, Ballard E, Osherow J, et al. Allowing adolescents and young adults to plan their end-of-life care. Pediatrics. 2012 Nov;130(5):897-905.

15 Brinkman-Stoppelenburg A, Rietjens JA, van der Heide A. The effects of advance care planning on end-of-life care: a systematic review. Palliat Med. 2014 Sep;28(8):1000-25.

16 Banner D, Freeman S, Kandola DK, Meikle M, Russell BK, Sommerfeld EA, et al. Community perspectives of end-of-life preparedness. Death Stud. 2019;43(4):211-23.

17 Lund S, Richardson A, May C. Barriers to advance care planning at the end of life: an explanatory systematic review of implementation studies. PLoS One. 2015 Feb; 10(2):e0116629.

18 Neimeyer RA, Wittkowski J, Moser RP. Psychological research on death attitudes: an overview and evaluation. Death Stud. 2004 May;28(4):309-40.

19 Tomer A. Death anxiety in adult life-theoretical perspectives. Death Stud. 1992;16(6): 475-506.

20 Menzies RE, Menzies RG. Death anxiety in the time of COVID-19: theoretical explanations and clinical implications. Cogn Behav Ther. 2020;13:e19. Available from: https:// www.cambridge.org/core/article/death-anxiety-in-the-time-of-covid19-theoretical-explanations-and-clinical-implications/3519F CFC320DA8821DD2E0EEB0B1EA5F

21 Fava GA, Cosci F, Sonino N. Current Psychosomatic Practice. Psychother Psychosom. 2017;86(1):13-30.

22 Iverach L, Menzies RG, Menzies RE. Death anxiety and its role in psychopathology: reviewing the status of a transdiagnostic construct. Clin Psychol Rev. 2014 Nov;34(7): 580-93.

23 Menzies RE, Sharpe L, Dar-Nimrod I. The relationship between death anxiety and severity of mental illnesses. Br J Clin Psychol. 2019 Nov;58(4):452-67.

24 Grassi L, Sabato S, Rossi E, Biancosino B, Marmai L. Use of the diagnostic criteria for psychosomatic research in oncology. Psychother Psychosom. 2005;74(2):100-7.

25 Sinoff G. Thanatophobia (death anxiety) in the elderly: the problem of the child's inability to assess their own parent's death anxiety state. Front Med (Lausanne). 2017 Feb;4:11. Available from: https://www.frontiersin.org/ article/10.3389/fmed.2017.00011

26 McGrath P. Affirming the connection: comparative findings on communication issues from hospice patients and hematology survivors. Death Stud. 2004 Nov;28(9):829-48.
27 Tong E, Deckert A, Gani N, Nissim R, Rydall A, Hales $S$, et al. The meaning of self-reported death anxiety in advanced cancer. Palliat Med. 2016 Sep;30(8):772-9.

28 Jimenez G, Tan WS, Virk AK, Low CK, Car J, Ho AH. Overview of Systematic Reviews of Advance Care Planning: Summary of Evidence and Global Lessons. J Pain Symptom Manage. 2018 Sep;56(3):436-459.e25.

29 Seifart C, Riera Knorrenschild J, Hofmann M, Nestoriuc Y, Rief W, von Blanckenburg P. Let us talk about death: gender effects in cancer patients' preferences for end-of-life discussions. Support Care Cancer. 2020 Oct;28(10): 4667-75.

30 Fried TR, Redding CA, Robbins ML, Paiva A, O'Leary JR, Iannone L. Stages of change for the component behaviors of advance care planning. J Am Geriatr Soc. 2010 Dec;58(12): 2329-36.

31 Barnes K, Jones L, Tookman A, King M. Acceptability of an advance care planning interview schedule: a focus group study. Palliat Med. 2007 Jan;21(1):23-8.

32 Hettema J, Steele J, Miller WR. Motivational interviewing. Annu Rev Clin Psychol. 2005; 1(1):91-111.

33 Nagelschmidt K, Leppin N, Seifart C, Rief W, von Blanckenburg P. Family communication barriers at end-of-life: a systematic mixed methods review. BMJ Support Palliat Care. Accepted. https://doi.org/10.1136/bmjspcare-2020-002219.

34 Caughlin JP, Mikucki-Enyart SL, Middleton $\mathrm{AV}$, Stone AM, Brown LE. Being open without talking about it: a rhetorical/normative approach to understanding topic avoidance in families after a lung cancer diagnosis. Commun Monogr. 2011;78(4):409-36.

35 Generous MA, Keeley M. Wished for and avoided conversations with terminally ill individuals during final conversations. Death Stud. 2017 Mar;41(3):162-72.

36 Walczak A, Butow PN, Bu S, Clayton JM. A systematic review of evidence for end-of-life communication interventions: who do they target, how are they structured and do they work? Patient Educ Couns. 2016 Jan;99(1): $3-16$.

37 Abba K, Byrne P, Horton S, Lloyd-Williams $M$. Interventions to encourage discussion of end-of-life preferences between members of the general population and the people closest to them - a systematic literature review. BMC Palliat Care. 2013 Nov;12(1):40.

38 Grossman CH, Brooker J, Michael N, Kissane D. Death anxiety interventions in patients with advanced cancer: A systematic review. Palliat Med. 2018 Jan;32(1):172-84.

39 Menzies RE, Zuccala M, Sharpe L, Dar-Nimrod I. The effects of psychosocial interventions on death anxiety: a meta-analysis and systematic review of randomised controlled trials. J Anxiety Disord. 2018 Oct;59:64-73. Available from: http://www.sciencedirect. com/science/article/pii/S0887618518302512
40 Chochinov HM, Hack T, Hassard T, Kristjanson LJ, McClement S, Harlos M. Dignity therapy: a novel psychotherapeutic intervention for patients near the end of life. J Clin Oncol. 2005 Aug;23(24):5520-5.

41 Mai SS, Goebel S, Jentschke E, van Oorschot B, Renner KH, Weber M. Feasibility, acceptability and adaption of dignity therapy: a mixed methods study achieving $360^{\circ}$ feedback. BMC Palliat Care. 2018 May;17(1):73.

42 Sudore RL, Fried TR. Redefining the "planning" in advance care planning: preparing for end-of-life decision making. Ann Intern Med. 2010 Aug;153(4):256-61.

43 Berlin P, Leppin N, Nagelschmidt K, Seifart C, Rief W, von Blanckenburg P. Development and validation of the readiness for end-of-life conversations (REOLC) scale. In preparation.

44 Wittkowski J. The construction of the multidimensional orientation toward dying and death inventory (MODDI-F). Death Stud. 2001 Sep;25(6):479-95.

45 Kroenke K, Spitzer RL, Williams JB. The PHQ-9: validity of a brief depression severity measure. J Gen Intern Med. 2001 Sep;16(9): 606-13.

46 Martínez M, Arantzamendi M, Belar A, Carrasco JM, Carvajal A, Rullán M, et al. 'Dignity therapy', a promising intervention in palliative care: A comprehensive systematic literature review. Palliat Med. 2017 Jun;31(6): 492-509.

47 Colosimo K, Nissim R, Pos AE, Hales S, Zimmermann C, Rodin G. "Double awareness" in psychotherapy for patients living with advanced cancer. J Psychother Integration. 2018;28(2):125-40

48 Simon J, Porterfield P, Bouchal SR, Heyland D. 'Not yet' and 'Just ask': barriers and facilitators to advance care planning-a qualitative descriptive study of the perspectives of seriously ill, older patients and their families. BM] Support Palliat Care. 2015 Mar;5(1):54-62.

49 Peterson LJ, Dobbs D, Meng H, Gamaldo A, O’Neil K, Hyer K. Sharing End-of-Life Care Preferences with Family Members: Who Has the Discussion and Who Does Not. J Palliat Med. 2018 Apr;21(4):463-72.

50 Wildfeuer J, Schnell MW, Schulz C. Talking about dying and death: on new discursive constructions of a formerly postulated taboo. Discourse Soc. 2015;26(3):366-90.

51 Schnell MW, Schulz-Quach C. 30 Gedanken - Eine öffentliche Diskursreihe zum Thema Sterben und Tod. In: Schnell MW, SchulzQuach C, editors. Basiswissen Palliativmedizin. Berlin, Heidelberg: Springer Berlin Heidelberg; 2019. pp. 303-6.

52 Schnell MW, Schulz C, Kuckartz U, Dunger C. Junge Menschen sprechen mit sterbenden Menschen: eine Typologie. Berlin: Springer; 2016 
53 Wong MK, Medor MC, Labre KY, Jiang M, Frank JR, Fischer LM, et al. Gaps in public preparedness to be a substitute decision-maker and the acceptability of high school education on resuscitation and end-of-life care: a mixed-methods study. CMAJ Open. 2019 Sep;7(3):E573-81.

54 Mroz E, Bluck S, Smith K. Young adults' perspectives on advance care planning: evaluating the Death over Dinner Initiative. Death Stud. Epub 2020 Feb.

55 Grevenstein D, Bluemke M. Who's afraid of death and terrorists? Investigating moderating effects of sense of coherence, mindfulness, neuroticism, and meaning in life on mortality salience. J Articles Supp Null Hypoth. 2016; 13(1):25-35.
56 Philipp R, Mehnert A, Lo C, Müller V, Reck $\mathrm{M}$, Vehling S. Characterizing death acceptance among patients with cancer. Psychooncology. 2019 Apr;28(4):854-62.

57 Strupp J, Köneke V, Rietz C, Voltz R. Perceptions of and attitudes toward death, dying, grief, and the finitude of life: a representative survey among the general public in Germany. Omega (Westport). 2019 Oct; 30222819882220.
58 Vehling S, Malfitano C, Shnall J, Watt S, Panday T, Chiu A, et al. A concept map of deathrelated anxieties in patients with advanced cancer. BMJ Support Palliat Care. 2017 Dec; 7(4):427-34.

59 Guidi J, Brakemeier EL, Bockting CL, Cosci F, Cuijpers P, Jarrett RB, et al. Methodological Recommendations for Trials of Psychological Interventions. Psychother Psychosom. 2018; 87(5):276-84.

60 Porcelli P, Guidi J. The Clinical Utility of the Diagnostic Criteria for Psychosomatic Research: A Review of Studies. Psychother Psychosom. 2015;84(5):265-72. 